\title{
Are religious beliefs and practices of Buddhism associated with disability and salivary cortisol in office workers with chronic low back pain?
}

\author{
Annop Sooksawat ${ }^{1}$, Prawit Janwantanakul ${ }^{1 *}$, Tewin Tencomnao $^{2}$ and Praneet Pensri ${ }^{1}$
}

\begin{abstract}
Background: Low back pain (LBP) is common among office workers. A number of studies have established a relationship between Christianity and physical and mental health outcomes among chronic pain patients. The purpose of this study was to examine the relationship between the religious beliefs and practices of Buddhism and disability and psychological stress in office workers with chronic LBP.

Methods: A cross-sectional survey was conducted with a self-administered questionnaire delivered by hand to 463 office workers with chronic LBP. Saliva samples were collected from a randomly selected sub-sample of respondents $(n=96)$. Disability due to LBP was assessed using the Roland-Morris Disability Questionnaire and psychological stress was assessed based on salivary cortisol. Two hierarchical regression models were built to determine how much variance in disability and psychological stress could be explained by religious beliefs and practices of Buddhism variables after controlling for potential confounder variables.

Results: Only $6 \%$ of variance in psychological stress was accounted for by the religious beliefs and practices of Buddhism. Those with high religiousness experienced lower psychological stress. No association between the religious beliefs and practices of Buddhism and disability level was found. Depressive symptoms were attributed to both psychological stress and disability status in our study population.

Conclusions: The findings suggest that, although being religious may improve the psychological condition in workers with chronic LBP, its effect is insufficient to reduce disability due to illness. Further research should examine the role of depression as a mediator of the effect of psychological stress on disability in patients with chronic LBP.
\end{abstract}

\section{Background}

It is well documented that psychosocial factors significantly influence low back pain (LBP), disability, and persistent symptoms [1,2]. Psychological stress has been shown to exacerbate pain in women with chronic pain, such as fibromyalgia syndrome [3]. Maladaptive pain cognitions, such as pain catastrophizing, cause fear of movement, which in turn contributes to activity avoidance and functional disability [4]. A systematic review suggests that depression is a strong predictor of poor LBP prognosis [5].

Previous studies among Christians showed that religion/spirituality was associated with positive psychological

\footnotetext{
* Correspondence: prawit.j@chula.ac.th

'Department of Physical Therapy, Faculty of Allied Health Sciences,

Chulalongkorn University, Bangkok, Thailand

Full list of author information is available at the end of the article
}

conditions [6]. Baetz and Bowen [7] found that chronic pain and fatigue sufferers who were both religious and spiritual were more likely to have better psychological wellbeing and use positive coping strategies than non-religious and non-spiritual sufferers. Abraido-Lanza et al. [8] reported a positive association between religious coping and psychological well-being in 200 patients with arthritis. Also, Baetz et al. [9] surveyed 70,884 Canadians and found that those who frequently attended worship services had lower levels of depressive symptoms.

Buddhism is one of the major world religions with most Buddhists living in Asia, particularly in the East and South-East Asia regions. According to the National Statistical Office, $94.2 \%$ of the Thai population is Buddhist [10]. Buddhism is a system of teaching aiming to eradicate the ultimate problem of mental suffering in life. Its teaching emphasizes the use of one's own wisdom to attain the

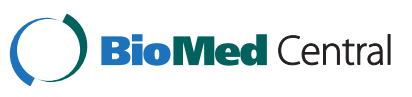


objective truth of nature and completely eliminate the origin of mental distress so that the mind can be released once and for all from suffering. Buddhism preaches that nature is a causally and conditionally interdependent system of phenomena, including the mind and body of man [11]. Mindfulness and meditation, which is the practice of paying attention, on purpose, moment-to-moment, in a way that is non-judgmental and non-reactive [12], are fundamentally parts of Buddhism. Several studies indicated a positive effect of mindfulness on pain catastrophizing, pain-related fear, hyper-vigilance, pain-related anxiety and, physical and psychological functioning [13-15]. Significant improvements in pain intensity, pain acceptance, psychological well-being and physical function have been reported in chronic pain patients following mindfulnessbased treatments [12,16]. The practice of continuous mindfulness has been proposed to facilitate the acquisition of adaptive thought and emotion-regulation skills, which reduces psychological inflexibility and expands behavioral repertoires to provide patients with more healthy options to deal with their own problems [13]. In addition, mindfulness enhances physical self-monitoring and body awareness, possibly leading to improved body mechanics and self-care [12].

To date, there has been no study on the effect of religious beliefs and practices of Buddhism on physical and mental health outcomes in chronic musculoskeletal patients, whose physical health is closely related to their psychosocial condition, such as chronic LBP patients. The purpose of this study was to examine the association between the religious beliefs and practices of Buddhism and disability and psychological stress in office workers with chronic LBP. Psychological stress was measured by salivary cortisol, which is routinely used as a biomarker of psychological stress and related mental or physical diseases. Salivary cortisol levels are considered a reliable measure of hypothalamus-pituitary-adrenal (HPA) axis adaptation to stress [17]. Evidence suggests that the HPA axis activity may play a role in the association between psychological variables and chronicity of pain [18]. It was hypothesized that the religious beliefs and practices of Buddhism would be associated with lower levels of disability and psychological stress in this group.

\section{Methods}

A cross-sectional study was conducted on office workers, who were defined as those working in an office environment with their main tasks involving using a computer, participating in meetings, giving presentations, reading, and phoning [19]. Office workers were included if they were Buddhist, aged between 18-60 years and had concurrent chronic LBP (i.e. LBP $\geq 3$ months duration either continuously or intermittently such that pain was experienced at least once per week [20]). The area of
LBP was defined according to the standardized Nordic questionnaire [21]. Subjects were excluded if they reported pregnancy or had a history of spinal surgery, trauma, or accidents. Subjects who had been diagnosed with congenital anomaly of the spine, rheumatoid arthritis, infection of the spine and discs, ankylosing spondylitis, lumbar spondylolisthesis, lumbar spondylosis, tumor, systemic lupus erythymatosus, or osteoporosis were also excluded from the study. Inclusion and exclusion criteria were determined by using a self-reported questionnaire.

An invitation letter and information about the study were sent to a convenience sample of office workers in 11 workplaces in Bangkok, Prachinburi and Singburi provinces in Thailand. The enterprises participating in this study were those in public transportation, infrastructure, energy, healthcare, insurance as well as the municipal office and ministerial head office. Those who expressed interest and who were eligible were invited to participate in the study. A self-administered questionnaire was then distributed to each eligible worker by hand and the researcher returned to collect the completed questionnaire 45 minutes later. In addition, saliva samples were collected from a sub-sample of respondents, who were randomly selected using a computergenerated random allocation sequence. Written informed consent was obtained from all participants and the study was approved by the University Human Ethics Committee.

Religious beliefs and practices of Buddhism questionnaire The religious beliefs and practices of Buddhism questionnaire is a reliably validated instrument developed by a team of Thai researchers [22]. The questionnaire consisted of 30 questions divided into three subscales: 10 items on belief in the Buddhist teachings, 10 items on Buddhist practice, and 10 items on the Buddhist lifestyle. Respondents are asked to what extent these statements are true for them. Items are scored on a 6-point Likert scale with responses ranging from 1 (absolutely untrue) to 6 (absolutely true). The total score of the test ranges from 30 to 180 , with higher scores indicating more spirituality or religiousness (Additional file 1).

The 10 items on belief in Buddhist teachings (Cronbach's alpha coefficient $=.83$; Construct validity using the known group technique $t$-test $=13.29, \mathrm{p}<.001$; Discrimination $\mathrm{t}$-ratio $=5.25$ to 11.08 ) assess an individual's belief in the three basic teachings of Buddhism as truth, namely 1) belief in the three sources of religious dependence, i.e. the Buddha, His teachings, and the Buddhist monk, 2) belief in the law of cause and effect, heaven and hell, and the cycle of birth and death, and 3) belief in Nirvana or the ultimate goal which can be achieved by a human being.

The 10 items on Buddhist practice (Cronbach's alpha coefficient $=.78$; Construct validity $t$-test $=6.02, \mathrm{p}<.01$; Discrimination t-ratio $=3.48$ to 10.48 ) measure an 
individual's action or restraint as relates to being a good Buddhist, namely 1) the act of giving, which includes donations, forgiving and delivering the Buddha's teachings to others, 2) the Five Precepts which are the sins of commission by words and deeds, and 3) praying and meditating.

The 10 items on Buddhist lifestyle (Cronbach's alpha coefficient $=.85$; Discrimination t-ratio $=6.41$ to 10.87 ) assess the extent to which an individual performs the activities of everyday life consonant with Buddhism principles.

\section{Fear-avoidance beliefs questionnaire}

The Fear-Avoidance Beliefs Questionnaire (FABQ) Thai version is a 16-item instrument containing two subscales: 7 items on fear avoidance beliefs about work and 4 items on fear avoidance beliefs about physical activity. Items are scored on a 7-point Likert scale with responses ranging from 0-6 (completely disagree to completely agree). The total score of the FABQ work scale ranges from 0 to 42 and the total score of the FABQ physical activities scale ranges from 0 to 24 . Higher scores indicate higher fear avoidance attitudes [23].

\section{Roland-morris disability questionnaire}

Disability level associated with LBP was assessed using the Roland-Morris Disability Questionnaire (RDQ) Thai version, which contains 24 yes/no items. Patients are asked whether the statements apply to them that day (the last 24 hours). The RDQ score is calculated by adding up the number of "yes" items, ranging from 0 to 24 , with higher scores indicating more severe disability [24].

\section{General information and confounder questionnaire}

This questionnaire comprised four sections designed to gather data on individual, work-related, and psychosocial factors as well as LBP characteristics. Individual factors included gender, age, height, body weight, educational level, marital status, frequency and duration of weekly exercise sessions, and smoking habits. Respondents were asked if they thought their work was physically demanding and whether they received work compensation due to LBP. Information about expectations of treatment or recovery was also sought.

Psychosocial factors were measured using the General Health Questionnaire (GHQ-28) Thai version, which is a 28-item measure of emotional distress in medical settings. The questions are grouped into four areas: somatic symptoms, anxiety and insomnia, social dysfunction, and severe depression. Each area has 7 questions with a score of 0 or 1 . The total score for each area ranges from 0 (better or same as usual symptoms for all questions) to 7 (worse or much worse than usual symptoms for all questions). A combination of scores from four areas with a score of 6 or more indicates a case of psychological distress [25].
Regarding LBP, subjects were asked about the duration of LBP, pain intensity using a numerical pain scale, and radiation of pain in the past 4 weeks.

\section{Salivary cortisol}

An individual's psychological stress was assessed based on salivary cortisol. Literature suggests that the integrated volume of cortisol released over the waking period is positively related to general life stress [26]. Participants received written and oral information about sampling details. The salivary sample was collected on the Wednesday of the week to reduce day-to-day variation in salivary cortisol by using a salivary sample collection set (IBL-America, Minneapolis, MN, USA). Participants collected two saliva samples: at awakening and $30 \mathrm{~min}$ after awakening. Participants were told not to brush their teeth and to refrain from eating and drinking before the end of sampling time. Participants were asked to abstain from food, alcohol, caffeine products, juice, and certain medicines (prednisone, dexamethasone, steroids, adrenergic agonist and antagonist) for at least 3 hours prior to saliva collection. Participants were also asked not to participate in any vigorous activity within 24 hours prior to sample collection. A salivary sample was not collected during a menstruation period. The salivary samples were stored in a $-20^{\circ} \mathrm{C}$ refrigerator until assayed.

The free cortisol concentration in saliva was measured using an enzyme-linked immunosorbent assay (ELISA) kit according to the manufacturer's instructions (IBLAmerica). All samples were assayed in duplicate and the average was used in analysis. To quantify the cortisol awakening response of each subject, the "area under the curve with respect to the ground" $\left(\mathrm{AUC}_{\mathrm{G}}\right)$ was calculated using the formula outlined by Pruessner et al. [27]. In this study, the two cortisol concentration measurements (i.e. at awakening and $30 \mathrm{~min}$ after awakening) represented $M_{1}$ and $M_{2}$ and time interval between the measurements was 30 min. Thus, the total $\mathrm{AUC}_{\mathrm{G}}$ can be calculated as: $(\mathrm{M} 1+\mathrm{M} 2) / 2 \times 30$.

Before data collection, the test-retest reliability of data from all questionnaires was assessed using 32 office workers. Each subject was tested twice on 2 separate days with a week lapse between the measurements. The intraclass correlation coefficient [ICC $(1,1)$ ] was used for continuous data. Kendall's tau-b and Phi were calculated for ordinal and nominal data, respectively.

\section{Statistical analyses}

Descriptive statistics were calculated for all variables. General characteristics of subjects in the main study $(n=463)$ and a randomly selected sub-sample of office workers $(n=96)$ were compared using the independent $t$-test and Chi-square for continuous and nominal/ ordinal data, respectively. 
Two separate hierarchical regression analyses were conducted to determine how much variance in the RDQ score and $\mathrm{AUC}_{\mathrm{G}}$ could be explained by the religious beliefs and practices of Buddhism variables after controlling for potential confounder variables. Correlational analyses were conducted first to examine the relationships among the religious beliefs and practices of Buddhism and each variable. For dichotomous variables, dummy variables were constructed before performing the correlational analysis. The variables chosen for inclusion in the regression analyses were those significantly correlated with the RDQ score and $\mathrm{AUC}_{\mathrm{G}}$ based on correlational analysis. All variables were entered in the first step and the religious beliefs and practices of Buddhism variable was entered in the second step. All statistical analyses were performed using SPSS statistical software, version 17.0 (SPSS Inc, Chicago, IL, USA). Statistical significance was set at the $5 \%$ level.

\section{Results}

\section{Test-retest reliability}

The reliability results demonstrated moderate to good reliability of questionnaire outcomes with the $\operatorname{ICC}(1,1)$ scores ranging from 0.75 to 0.92 , Kendall's tau-b ranging from 0.76 to 0.87 and Phi ranging from 0.85 to 1.00 .

\section{Subjects' characteristics}

There were 2,890 office workers who were approached to participate in the study with 2,250 accepting the invitation (a response rate of $77.8 \%$ ). Of 2,250 workers, 519 were eligible, but only 463 agreed to participate in this study. They were asked to complete the selfadministered questionnaire. Of the 463 workers, 102 were randomly selected but only 96 agreed to collecting their saliva samples (a response rate of 94.1\%). Table 1 presents the demographic, LBP, health outcomes, and the Buddhist characteristics of the religious beliefs and practices of the study population. A small number of office workers agreed that their job was physically demanding (21.4\%) and received work compensation due to their LBP (15.8\%). About 52.1\% agreed or strongly agreed that their LBP would completely resolve itself. Mean cortisol levels at awakening for those with higher and lower/equal to the mean total scores of the religious beliefs and practices of Buddhism questionnaire (132.8) were 5.41 and $6.65 \mu \mathrm{g} / \mathrm{dL}$, respectively. Mean cortisol levels at $30 \mathrm{~min}$ after awakening for those with higher and lower/equal to mean total scores than the mean total scores of the religious beliefs and practices of Buddhism questionnaire (132.8) were 7.19 and $8.57 \mu \mathrm{g} / \mathrm{dL}$, respectively and $30 \mathrm{~min}$ after awakening were divided into two groups based on mean total score derived from.

\section{Association between disability and the religious beliefs and practices of Buddhism ( $n=463$ )}

A model was constructed to establish the association between disability and the religious beliefs and practices of Buddhism (Table 2). When correlational analysis was used, LBP duration, pain intensity in the past 4 weeks, radiation of pain in the past 4 weeks, expectation of treatment or recovery, anxiety, depression, FABQ physical activity and FABQ work subscale were significantly correlated with the RDQ score. The final model explained $27 \%$ of the total variance in disability. Twenty-seven percent of variance in disability was accounted for by LBP duration, pain intensity in the past 4 weeks, radiation of pain in the past 4 weeks, depression, FABQ physical activity score, and FABQ work score. No further variance in disability was explained by the religious beliefs and practices of Buddhism after controlling for confounder variables.

\section{Association between psychological stress and the religious beliefs and practices of Buddhism $(n=96)$}

A model was constructed to establish the association between psychological stress and the religious beliefs and practices of Buddhism (Table 3). When correlational analysis was used, gender, age, education and depression were significantly correlated with $\mathrm{AUC}_{\mathrm{G}}$. The final model explained $25 \%$ of the total variance in psychological stress. Nineteen percent of variance in psychological stress was accounted for by gender, age, education, and depression. The religious beliefs and practices of Buddhism accounted for an additional and significant $6 \%$ of variance in psychological stress, after controlling for confounder variables.

\section{Discussion}

The analysis of the relationship between the religious beliefs and practices of Buddhism and disability and psychological stress in office workers with chronic LBP revealed that the religious beliefs and practices of Buddhism were significantly associated with psychological stress but not with disability. Workers with high religious beliefs and practices of Buddhism had lower psychological stress. The findings confirm the results of previous studies regarding the effect of religious beliefs and practices of Christianity on psychological conditions [7-9]. A number of hypotheses have been proposed to explain the improvement of psychological conditions due to religious and spiritual practices. These hypotheses have focused on the influence of religious and spiritual practices on neural pathways and social aspects as well as the increase in mindfulness. Positive emotions, such as forgiveness, hope, contentment, love, may reduce the arousal in the endocrine and immune systems and the hypothalamus-pituitary-adrenal axis system, which help increase immune competence and restore physiological stability [28]. Religious or spiritual practices provide opportunities for fellowship, involvement in formal 
Table 1 Demographic, low back pain, health outcomes, and the Buddhist characteristics of the religious beliefs and practices of participating office workers with chronic low back pain

\begin{tabular}{|c|c|c|c|c|c|}
\hline \multirow[t]{2}{*}{ Characteristics } & \multicolumn{2}{|c|}{$(n=463)$} & \multicolumn{2}{|c|}{$(n=96)$} & \multirow[b]{2}{*}{ P-value } \\
\hline & $\mathrm{N}(\%)$ & Mean (SD) & $\mathrm{N}(\%)$ & Mean (SD) & \\
\hline \multicolumn{6}{|l|}{ Demographic characteristics } \\
\hline Age & & $38.5(10.0)$ & & $36.5(9.1)$ & 0.55 \\
\hline Gender & & & & & 0.69 \\
\hline Male & $113(24.4)$ & & $32(33.3)$ & & \\
\hline Female & $350(75.6)$ & & $64(66.7)$ & & \\
\hline Body mass index $\left(\mathrm{kg} / \mathrm{m}^{2}\right)$ & & $23.1(3.9)$ & & $23.8(4.5)$ & 0.16 \\
\hline Education & & & & & 0.42 \\
\hline Lower than Bachelor's degree & $80(17.3)$ & & $14(14.5)$ & & \\
\hline Bachelor's degree & $298(64.4)$ & & $59(61.5)$ & & \\
\hline Higher than Bachelor's degree & $85(18.3)$ & & $23(24.0)$ & & \\
\hline Exercise frequency in the past 12 months & & & & & 0.34 \\
\hline Never & $123(26.6)$ & & $31(32.3)$ & & \\
\hline Occasionally & $288(62.2)$ & & $52(54.2)$ & & \\
\hline Regularly & $52(11.2)$ & & $13(13.5)$ & & \\
\hline \multicolumn{6}{|l|}{ Low back pain characteristics } \\
\hline Duration of low back pain (months) & & $28.3(36.9)$ & & $27.8(36.9)$ & 0.89 \\
\hline Pain intensity in the past 4 weeks using NPS & & $4.3(1.8)$ & & $4.3(1.8)$ & 0.87 \\
\hline Radiation of pain in the past 4 weeks & & & & & 0.74 \\
\hline Yes & $137(39.6)$ & & $30(31.2)$ & & \\
\hline No & $326(70.4)$ & & $66(68.8)$ & & \\
\hline \multicolumn{6}{|l|}{ Health outcomes } \\
\hline RDQ-24 & & $4.8(3.8)$ & & $5.1(3.6)$ & 0.40 \\
\hline FABQ work subscale & & $17.8(7.8)$ & & $16.7(7.6)$ & 0.21 \\
\hline FABQ physical activity subscale & & $14.5(4.5)$ & & $14.6(4.4)$ & 0.72 \\
\hline GHQ-28 & & $4.6(5.0)$ & & $5.0(5.5)$ & 0.47 \\
\hline Anxiety subscale & & $1.3(2.0)$ & & $1.4(2.2)$ & 0.77 \\
\hline Depression subscale & & $0.2(0.8)$ & & $0.4(1.0)$ & 0.13 \\
\hline $\mathrm{AUC}_{\mathrm{G}}($ cortisol) $(\mu \mathrm{g} \cdot \mathrm{min} / \mathrm{dL})$ & & - & & $208.2(79.8)$ & - \\
\hline Cortisol level at awakening & & - & & $6.02(2.5)$ & \\
\hline Cortisol level at 30 min after awakening & & - & & $7.87(3.4)$ & \\
\hline \multicolumn{6}{|l|}{ Religious beliefs and practices of Buddhism } \\
\hline Total score & & $135.1(14.9)$ & & $132.8(15.1)$ & 0.17 \\
\hline Beliefs in Buddhist teaching subscale & & $43.5(6.1)$ & & $42.0(6.1)$ & 0.05 \\
\hline Buddhist practice subscale & & $47.6(6.3)$ & & $46.4(6.9)$ & 0.09 \\
\hline Buddhist lifestyle subscale & & $43.9(6.2)$ & & $43.3(6.3)$ & 0.63 \\
\hline
\end{tabular}

NPS, numerical pain scale; RDQ-24, the Roland-Morris Disability Questionnaire; FABQ, Fear-Avoidance Beliefs Questionnaire; GHQ-28, the General Health Questionnaire; $A \cup C_{G}$, area under the curve with respect to ground.

social programs, and companionship, thus helping reduce both psychological and physical stressors [29]. Religious or spiritual practices may increase mindfulness, which reduces psychological inflexibility through an improvement in 'focused attention' and facilitation of adaptive thought and emotion-regulation skill acquisition [13,14].
However, based on the results of the present study, the effect of religious beliefs and practices of Buddhism on psychological stress was rather subtle (6\%). Rippentrop et al. [30] conducted a study in chronic musculoskeletal pain patients with the majority of patients being Christian and found that $12 \%$ of variance in mental health status, 
Table 2 Hierarchical regression analysis predicting disability due to low back pain

\begin{tabular}{|c|c|c|c|c|c|}
\hline & & $R^{2}$ & $\begin{array}{c}R^{2} \\
\text { increment } \\
\text { for block }\end{array}$ & $\begin{array}{c}\text { Standard } \\
\beta\end{array}$ & $\begin{array}{c}F \\
\text { increment }\end{array}$ \\
\hline \multirow[t]{9}{*}{$\begin{array}{l}\text { Step } \\
1\end{array}$} & $\begin{array}{l}\text { Potential } \\
\text { confounders for } \\
\text { disability }\end{array}$ & .27 & & & $21.86^{* * *}$ \\
\hline & LBP duration & & & $.16^{* * *}$ & \\
\hline & $\begin{array}{l}\text { Pain intensity in } \\
\text { the past } 4 \text { weeks }\end{array}$ & & & $.20^{* * *}$ & \\
\hline & $\begin{array}{l}\text { Radiation of pain } \\
\text { in the past } 4 \text { weeks }\end{array}$ & & & $.14^{* *}$ & \\
\hline & $\begin{array}{l}\text { Expectation of } \\
\text { treatment or } \\
\text { recovery }\end{array}$ & & & -.07 & \\
\hline & Anxiety & & & .06 & \\
\hline & Depression & & & $.16^{* *}$ & \\
\hline & $\begin{array}{l}\text { FABQ physical } \\
\text { activity subscale }\end{array}$ & & & $.09^{*}$ & \\
\hline & $\begin{array}{l}\text { FABQ work } \\
\text { subscale }\end{array}$ & & & $.14^{* *}$ & \\
\hline \multirow[t]{2}{*}{$\begin{array}{l}\text { Step } \\
2\end{array}$} & $\begin{array}{l}\text { Religious beliefs } \\
\text { and practices of } \\
\text { Buddhism }\end{array}$ & .27 & .00 & & 0.51 \\
\hline & Total scale & & & .02 & \\
\hline
\end{tabular}

Overall model $R^{2}=.279(F=19.46, P=.000)$.

Betas are standardized. ${ }^{*} P<.05 ;{ }^{*} P<.01 ;{ }^{* * *} P<.001$.

LBP, low back pain; FABQ, Fear-Avoidance Beliefs Questionnaire.

measured by the SF-36, among the study sample was accounted for by forgiveness, negative religious coping, daily spiritual experiences, religious support, and spiritual/ religiousness intensity. Our findings indicate that the application of religious beliefs and practices to the improvement of psychological conditions in the patient population may be limited. However, only a few selected psychological factors were examined in the present and previous studies.

Table 3 Hierarchical regression analysis predicting physiological stress

\begin{tabular}{|c|c|c|c|c|c|}
\hline & & $R^{2}$ & $\begin{array}{l}R^{2} \text { increment } \\
\text { for block }\end{array}$ & $\underset{\beta}{\text { Standard }}$ & $\begin{array}{c}F \\
\text { increment }\end{array}$ \\
\hline \multirow[t]{5}{*}{$\begin{array}{l}\text { Step } \\
1\end{array}$} & $\begin{array}{l}\text { Potential } \\
\text { confounders }\end{array}$ & .19 & & & $5.50^{* *}$ \\
\hline & Gender & & & $.24^{*}$ & \\
\hline & Age & & & $.21^{*}$ & \\
\hline & Education & & & $.22^{*}$ & \\
\hline & Depression & & & $.27^{* *}$ & \\
\hline \multirow[t]{2}{*}{$\begin{array}{l}\text { Step } \\
2\end{array}$} & $\begin{array}{l}\text { Religious beliefs } \\
\text { and practices of } \\
\text { Buddhism }\end{array}$ & .25 & $.06^{* *}$ & & $7.34^{* *}$ \\
\hline & Total scale & & & $-.25^{* *}$ & \\
\hline
\end{tabular}

Overall model $R^{2}=.255(F=6.17, P=.000)$.

Betas are standardized. ${ }^{*} P<.05 ;{ }^{* *} P<.01 ;{ }^{* * *} P<.001$.
Other important psychological factors that relate to the religious beliefs and practices may be identified in future work.

Several factors were found to significantly associate with disability due to LBP, including duration of LBP, pain intensity in the past 4 weeks, radiation of pain in the past 4 weeks, depression, and fear-avoidance beliefs. However, no association between the religious beliefs and practices of Buddhism and disability was found. Johnstone and Yoon [31] found no association between religiousness/spirituality and physical health in 118 individuals with chronic disabilities, including traumatic brain injury, cerebral vascular accidents and spinal cord injury. Rippentrop et al. [30] reported that only $3 \%$ of variance in physical health status, measured by the SF-36, was accounted for by private religious practices in chronic musculoskeletal pain patients. The authors hypothesized that patients with poor physical health relied on their faith for comfort and, thus, private religious activity was a result of increasing physical disability. These findings suggest that, although being religious may improve psychological condition, its effect is insufficient to reduce disability due to illness, at least in our sample of office workers with chronic LBP. However, our study population of office workers with chronic LBP had a low disability level (average RDQ scores of 4.8/24), which is in contrast with that of Turner et al. [32] who reported a moderate level of disability (the mean RDQ score $=12.7 / 24$ ) for those workers submitting work compensation claims for work-related back pain. This discrepancy may be due to the difference in subject characteristics and occupation. In the previous study, the sample was workers who ceased working because of their LBP condition while in the present study the office workers were still engaged in their work. Workers who keep working should have low disability because it would be difficult for them to remain productive at moderate to high disability levels [33]. Also, the present study only recruited office workers while the previous study included workers from different occupations. Office work is sedentary which mainly involves computer use, participation in meetings, giving presentations, reading, and phoning [19]. Only $21 \%$ of participating office workers reported that their job was physically demanding. As a result, we hypothesized that office workers were less likely to have moderate to high disability levels because of their limited physical requirements at work. Thus, extrapolation of the results to chronic LBP office workers with moderate to high disability should be undertaken with caution. Different results may emerge with those having moderate to high disability levels. Further research on the effect of religion/ spirituality on physical and mental health in those seeking treatment is recommended. 
Interestingly, based on hierarchical multiple regression models, we found that depression was only an investigated variable significantly associated with both psychological stress and disability levels in our study population of office workers with chronic LBP. Office workers with high depressive symptoms had high psychological stress and disability levels, which is consistent with the findings from previous studies [34,35]. Nearly $50 \%$ of chronic pain patients suffer from serious depression [36]. Depression, which is characterized by low positive affection and loss of self-esteem, potentially decreases the motivation for activity and thus affects productivity and disability [37]. Religion/spirituality, which has a positive effect on mental health, may partly reduce depression and consequently benefit patients' physical health. Further research is required to investigate the long-term effect of reduced psychological stress on disability level in chronic LBP patients.

The current study has several weak points. First, saliva samples were collected from a randomly selected subsample of office workers participating in this study. Nevertheless, their characteristics were very similar to a larger sample of office workers $(n=463)$ who participated in this study. Also, salivary sampling in field studies relies on the participants themselves to collect their samples. Thus, it is possible that participants did not collect samples precisely when they were instructed to do so. Second, the cross-sectional study design only allows the association between exposure and outcome to be examined. It is not possible to establish a causal relationship between exposure and outcome. Therefore, a prospective study design is required to validate the findings of this study. Third, this study may be susceptible to the "healthy worker effect". Office workers suffering from musculoskeletal injury due to work may move on to other jobs and therefore would have been missed during the sampling process in the present study. On the other hand, those workers remaining may be those who have experienced only mild to moderate levels of disability, which are not enough to warrant leaving or changing the job. Considering the low mean RDQ-24 score in the sample of this study, this is certainly a possibility. Forth, disability due to LBP in different occupations is unlikely to be identical because the physical requirements for different occupations are different. Thus, the association between the religious beliefs and practices of Buddhism and disability could be different among different working populations. Generalization of the results from this study to other populations should be made with caution. Lastly, the present study reported on socially undesirable behavior specifically in terms of the religious beliefs and practices, which may have led to bias. Future studies should consider inclusion of objective information to increase accuracy.

\section{Conclusions}

The current study examined the relationships between the religious beliefs and practices of Buddhism and disability and psychological stress in office workers with chronic LBP. Disability due to LBP was assessed using the Roland-Morris Disability Questionnaire and psychological stress was assessed based on salivary cortisol. We found that the religious beliefs and practices of Buddhism have a significant effect on psychological stress but not disability due to LBP. Chronic LBP office workers with high religiousness experienced lower psychological stress. The findings support the notion that religion/ spirituality is associated with positive psychological conditions. We also found that depressive symptoms were associated with both psychological stress and disability status. Thus, depression may be a mediator of the effect of psychological stress on disability in patients with chronic LBP. The findings from this study add to the mounting empirical evidence that the body and mind are inextricably linked and an effective treatment for chronic LBP should incorporate both physical and mental health interventions. However, there is much need for continued research to learn about the complex relationship between religion/spirituality and health.

\section{Additional file}

Additional file 1: Religious Beliefs and Practices of Buddhism Questionnaire.

\section{Competing interests}

The authors declare that there are no conflicts of interest.

\section{Authors' contributions}

The authors have contributed in the following ways: AS provided concept/research design, data collection, data analysis and manuscript writing. PJ provided concept/research design, data analysis and manuscript writing. TT and PP provided concept/research design and manuscript writing. All authors read and approved the final manuscript.

\section{Acknowledgements}

This study was supported by the $90^{\text {th }}$ Anniversary of Chulalongkorn University Fund (Ratchadaphiseksomphot Endowment Fund) and the Chulalongkorn University Centenary Academic Development Project (\#12). We also would like to thank Varaporn Rakkhitawatthana for her technical assistance.

\section{Author details}

${ }^{1}$ Department of Physical Therapy, Faculty of Allied Health Sciences, Chulalongkorn University, Bangkok, Thailand. ${ }^{2}$ Center for Excellence in Omics-Nano Medical Technology Development Project, Department of Clinical Chemistry, Faculty of Allied Health Sciences, Chulalongkorn University, Bangkok, Thailand.

Received: 28 August 2012 Accepted: 14 January 2013 Published: 17 January 2013

\section{References}

1. Hill JC, Fritz JM: Psychosocial influences on low back pain, disability, and response to treatment. Phys Ther 2011, 91:712-721. 
2. Manchikanti L, Fellows B, Singh V, Pampati V: Correlates of Non-Physiological Behavior in Patients with Chronic Low Back Pain. Pain Physician 2003, 6:159-166.

3. Davis MC, Zautra AJ, Reich JW: Vulnerability to stress among women in chronic pain from fibromyalgia and osteoarthritis. Ann Behav Med 2001, 23:215-226.

4. Leeuw M, Goossens ME, Linton SJ, Crombez G, Boersma K, Vlaeyen JW: The fear-avoidance model of musculoskeletal pain: current state of scientific evidence. J Behav Med 2007, 30:77-94.

5. Pincus T, Vogel S, Burton AK, Santos R, Field AP: Fear avoidance and prognosis in back pain: a systematic review and synthesis of current evidence. Arthritis Rheum 2006, 54:3999-4010.

6. Oman D, Thoresen CE: 'Does religion cause health?' Differing interpretations and diverse meanings. J Health Psychol 2002, 7:365-380.

7. Baetz M, Bowen R: Chronic pain and fatigue: Association with religion and spirituality. Pain Res Manage 2008, 13:383-388.

8. Abraodo-Lanza AF, Vasquez E, Echeverroa SE: En las Manos de Dios [in God's Hands]: Religious and other forms of coping among Latinos with arthritis. J Consult Clin Psychol 2004, 72:91-102.

9. Baetz M, Griffin R, Bowen R, Koenig HG, Marcoux E: The association between spiritual and religious involvement and depressive symptoms in a Canadian population. J Nerv Ment Dis 2004, 192:818-822.

10. The National Statistical Office: Statistics in Thailand. [Online]. [cited 2011 Dec 9]; Available from; 2009. URL: http://service.nso.go.th/nso/thailand/ thailand.jsp.

11. Payutto PA: Dhamma Bilingualized. Bangkok: Panya-pawana; 2010.

12. Rosenzweig S, Greeson JM, Reibel DK, Green JS, Jasser SA, Beasley D: Mindfulness-based stress reduction for chronic pain conditions: Variation in treatment outcomes and role of home meditation practice. J Psychosom Res 2010, 68:29-36.

13. Cho S, Heiby EM, McCracken LM, Lee SM, Moon DE: Pain-related anxiety as a mediator of the effects of mindfulness on physical and psychosocial functioning in chronic pain patients in Korea. J Pain 2010, 11:789-797.

14. McCracken LM, Gauntlett-Gilbert J, Vowles KE: The role of mindfulness in a contextual cognitive-behavioral analysis of chronic pain-related suffering and disability. Pain 2007, 131:63-69.

15. Schutze R, Rees C, Preece $M$, Schutze M: Low mindfulness predicts pain catastrophizing in a fear-avoidance model of chronic pain. Pain 2010, 148:120-127.

16. Kabat-Zinn J, Lipworth L, Burney R: The clinical use of mindfulness meditation for the self-regulation of chronic pain. J Behav Med 1985, 8:163-190.

17. Hellhammer DH, Wust S, Kudielka BM: Salivary cortisol as a biomarker in stress research. Psychoneuroendocrinology 2009, 34:163-171.

18. Sudhaus S, Fricke B, Stachon A, Schneider S, Klein H, von Düring M, Hasenbring M: Salivary cortisol and psychological mechanisms in patients with acute versus chronic low back pain. Psychoneuroendocrinology 2009, 34:513-522.

19. IJmker S, Blatter BM, van der Beek AJ, van Mechelen W, Bongers PM: Prospective research on musculoskeletal disorders in office workers (PROMO): Study protocol. BMC Musculoskelet Disord 2006, 7:55.

20. Briggs AM, Jordan JE, Buchbinder R, Burnett AF, O'Sullivan PB, Chua JY Osborne RH, Straker LM: Health literacy and beliefs among a community cohort with and without chronic low back pain. Pain 2010, 150:275-283.

21. Kuorinka I, Jonsson B, Kilbom A, Vinterberg $H$, Biering-Sorensen F, Andersson G, Jorgensen K: Standardised Nordic questionnaires for the analysis of musculoskeletal symptoms. Appl Ergon 1987, 18:233-237.

22. Bhanthumnavin D, Vanindananda N: Religious belief and practice of Thai Buddhists: Socialization and quality of life. Bangkok: National Research Council; 1997

23. Waddell G, Newton M, Henderson I, Somerville D, Main CJ: A FearAvoidance Beliefs Questionnaire (FABQ) and the role of fear-avoidance beliefs in chronic low back pain and disability. Pain 1993, 52:157-168.

24. Pensri P, Baxter G, McDonough S: Reliability and internal consistency of the Thai version of Roland-Morris disability questionnaire and Waddell disability Index for back pain patients. Chula Med J 2005, 49:333-349.

25. Nilchaikovit T, Sukying C, Silpakit C: Reliability and validity of the Thai version of the General Health Questionaire. J Psychiatr Assoc Thailand $1996,41: 2-17$
26. Chida Y, Steptoe A: Cortisol awakening response and psychosocial factors: a systematic review and meta-analysis. Biol Psychol 2009 80:265-278.

27. Pruessner JC, Kirschbaum C, Meinlschmid G, Hellhammer DH: Two formulas for computation of the area under the curve represent measures of total hormone concentration versus time-dependent change.

Psychoneuroendocrionology 2003, 28:916-931.

28. Thoresen CE: Spirituality and health: is there a relationship? J Health Psychol 1999, 4:291-300.

29. Seybold KS, Hill PC: The Role of Religion and Spirituality in Mental and Physical Health. Curr Dir Psychol Sci 2001, 10:20-24.

30. Rippentrop EA, Altmaier EM, Chen JJ, Found EM, Keffala VJ: The relationship between religion/spirituality and physical health, mental health, and pain in a chronic pain population. Pain 2005, 116:311-321

31. Johnstone $B$, Yoon DP: Relationships between the brief multidimensional measure of religiousness/spirituality and health outcomes for a heterogeneous rehabilitation population. Rehabil Psychol 2009, 54:422-431.

32. Turner JA, Franklin G, Fulton-Kehoe D, Sheppard L, Wickizer TM, Wu R, Gluck JV, Egan K: Worker recovery expectations and fear-avoidance predict work disability in a population-based workers' compensation back pain sample. Spine (Phila Pa 1976) 2006, 31:682-689.

33. Johnston V, Souvlis T, Jimmieson NL, Jull G: Associations between individual and workplace risk factors for self-reported neck pain and disability among female office workers. Appl Ergon 2008, 39:171-182.

34. Poleshuck EL, Bair MJ, Kroenke K, Damush TM, Tu W, Wu J, Krebs EE, Giles DE: Psychosocial stress and anxiety in musculoskeletal pain patients with and without depression. Gen Hosp Psychiatry 2009, 31:116-122.

35. Woby SR, Roach NK, Urmston M, Watson PJ: The relation between cognitive factors and levels of pain and disability in chronic low back pain patients presenting for physiotherapy. Eur J Pain 2007, 11:869-877.

36. Ruoff GE: Depression in the patient with chronic pain. J Fam Pract 1996, 43:S25-33.

37. Hall AM, Kamper SJ, Maher CG, Latimer J, Ferreira ML, Nicholas MK: Symptoms of depression and stress mediate the effect of pain on disability. Pain 2011, 152:1044-1051.

doi:10.1186/1471-2474-14-29

Cite this article as: Sooksawat et al:: Are religious beliefs and practices of Buddhism associated with disability and salivary cortisol in office workers with chronic low back pain? BMC Musculoskeletal Disorders 2013 $14: 29$.

\section{Submit your next manuscript to BioMed Central and take full advantage of:}

- Convenient online submission

- Thorough peer review

- No space constraints or color figure charges

- Immediate publication on acceptance

- Inclusion in PubMed, CAS, Scopus and Google Scholar

- Research which is freely available for redistribution 